\title{
Down regulation of miR-143 is related with tumor size, lymph node metastasis and HPV16 infection in cervical squamous cancer
}

\author{
Yanxia Chen ${ }^{1}$, Cailing Ma ${ }^{1 *}$, Wei Zhang ${ }^{2}$, Zhifang Chen ${ }^{1}$ and Li Ma ${ }^{1}$
}

\begin{abstract}
Objective: This study is to investigate the role of miR-143 expression in cervical squamous cell carcinoma (SCC).

Methods: The expression level of miR-143 was examined by quantitative real-time PCR. Human papillomavirus (HPV) genotype was detected by HPV genotype detection kit. The expression level of bcl-2 was detected by immunohistochemistry.
\end{abstract}

Results: The positive rate of HPV was 78\% in the patients of cervical SCC. The most prevalent genotype was HPV16, with a positive rate of $42 \%$. The expression level of miR-143 was significantly lower in the cervical SCC tissues than that in the normal cervical tissues $(Z=-2.180, P=0.029)$. Down-regulated miR-143 expression was associated with tumor size, lymph node metastasis and HPV16 infection in cervical cancer patients. No significant associations were found between the expression levels of miR-143 and age, clinical stage, differentiation or lymph vascular space invasion. And, in cervical SCC patients after treatment with Taxol chemotherapy, the expression level of miR-143 was higher and the positive expression of bcl-2 protein was lower. However, the differences in expression changes of miR-143 and bcl-2 were not statistically significant (miR-143, $Z=-0.763, P=0.446 ; b c l-2$ protein, $X^{2}=2.277, P=0.131$ ).

Conclusion: Down-regulated miR-143 is related with tumor size, lymph node metastasis and HPV16 infection in cervical SCC, but miR-143 does not participate in the Taxol sensitivity response.

Virtual slides: The virtual slide(s) for this article can be found here: http://www.diagnosticpathology.diagnomx.eu/vs/ 1401279451112150.

\section{Introduction}

Cervical cancer is caused by the activation of oncogenes and the inactivation of tumor suppressor genes, which are induced by carcinogens through different mechanisms. Persistent infection of the human papillomavirus (HPV) is an important factor causing cervical cancer. Genes of E6 and E7 of HPV are able to inactivate the cellular tumor suppressor genes and induce the over expression of the anti-apoptotic genes. Besides HPV, factors from host cells are also critical in the process of cervical malignant transformation. MicroRNAs (miRNAs) are a class of small, endogenous, single-stranded, non-coding RNA molecules, which can regulate cell proliferation, differentiation and apoptosis through targeting

\footnotetext{
* Correspondence: chenyanxiacyx@sina.cn

'Department of Gynecology, the First Affiliated Hospital of Xinjiang Medical University, No. 137 Liyushan South Road, Urumqi, Xinjiang 830054, P.R. China Full list of author information is available at the end of the article
}

specific genes. Thus they might be involved in carcinogenesis or tumor suppression. Abnormal expression of miR-143 is observed in many types of tumors, and it is involved in the tumor responses to chemotherapy [1]. Bcl-2 is the major target of miR-143. It is reported that HPV infection may alter miRNA profiles in squamous cell carcinoma of the head and neck cell lines [2]. Lajer et al. found that the miR-143/miR-145 may be involved in the pathogenesis of HPV-related head and neck cancer and cervical cancer [3]. Wang et al. showed that miR-143 and miR-145 expression was down-regulated in cervical cancer tissues and HPV-infected raft tissues with pre-neoplastic lesions. Overexpression of miR-143 and miR-145 suppressed HeLa cell growth. Their findings suggest that down regulation of miR-143 and miR-145 may favor cell growth of cervical cancer [4]. Georgios et al. found that miR-143 expression did not correlate with 
histology of cervical cancer [5]. Therefore, miR-143 plays an important role in cervical cancer.

Neoadjuvant chemotherapy (NACT) provides surgical opportunities for some patients, with enhanced efficacy of surgery and radiotherapy [6]. It is reported that miRNAs are involved in drug resistance of cancer cells. For example, Zhang et al. studied the miRNA signature in stage II colon cancer using miRNA microarrays. They found that six miRNAs, including miR-21-5p, miR-20a5p, miR-103a-3p, miR-106b-5p, miR-143-5p, and miR215 , might be able to predict which patients benefit from adjuvant chemotherapy [7]. Borralho et al. reported that miR-143 increased the sensitivity of HCT116 human colorectal cancer cells to 5 -fluorouracil, probably through extracellular-regulated protein kinase 5/nuclear factorkappaB regulated pathways [8]. Xu et al. found that miR143 enhanced the sensitivity of prostate cancer cells to docetaxel [9]. However, little is known about the role of miR-143 in modulating the cervical cancer cell response to Taxol.

The incidence rate of cervical cancer among the Uighur in the Xinjiang Uygur Autonomous Region is three to four times of that in Han race. And there are more cases in the Xinjiang Uygur Autonomous Region with advanced stages of cervical cancer. This study aims to investigate the role of miR-143 expression in cervical SCC through detecting miR-143 expression, analyzing the relationship between miR-143 expression and clinical pathological features of cervical cancer, and assessing the sensitivity of miR-143 and bcl-2 expression to Taxol treatment. Therefore, in this study, the miR-143 expression levels in cervical tumors infected with different HPV genotypes and in the cervical cancer tissues before and after NACT treatment were detected. Then the relationship between the miR-143 and the clinical and pathological features of cervical squamous cell carcinoma (SCC) in Uighur was analyzed. Additionally, the expression of miR-143 and its target protein bcl- 2 was also assessed.

\section{Materials and methods Clinical data}

Paraffin-embedded cervical tissues from 97 patients were collected in this study. The 97 patients were hospitalized from June 2010 to January 2012 in First Teaching Hospital of Xinjiang Medical University. Among them, 20 control patients had normal cervixes and 77 patients had cervical SCC. Patients with cervical SCC were newly diagnosed SCC cases, and did not receive radiotherapy or chemotherapy before surgery. The clinical pathological data of the 77 cervical SCC patients were shown in Table 1. The clinical data for 20 control patients was shown in Table 2. Exfoliated cervical cells were collected and the genotypes of HPV were classified by blind detection. Among the patients with cervical SCC, there were 59 patients who underwent radical hysterectomy and pelvic lymphadenectomy, and 18 patients who underwent cervical biopsy. And there were 16 cases at stage I, 43 cases at stage II, and 18 cases at stage III-IV; 27 well differentiated cases and 50 moderate and poor differentiated cases; 23 patients with tumor diameters > $4 \mathrm{~cm}$, and 54 patients with tumor diameters $\leq 4 \mathrm{~cm} ; 43$ cases without lymph node metastasis, and 16 cases with lymph node metastasis; 13 cases of lymph vascular space invasion (LVSI), and 46 cases without LVSI. The normal cervical tissues were collected from patients who underwent uterus hysterectomy because of myoma. Ages of the patients with normal cervixes ranged from 30 to 76 years old, with the mean age of 45 years old; and those of the cervical SCC patients ranged from 27 to 80 years old, with the mean age of 47 years old. There was no statistical significance in age between patients with normal cervical tissues and patients with cervical SCC.

Fresh cervical tissues from another 34 cervical SCC patients who were hospitalized in the hospital from January 2012 to December 2012 for pre-surgical chemotherapy were also selected. They were diagnosed as stage I b2 - II b cervical SCC by at least two co-chief physicians. They were treated with NACT before surgery. Clinical data of 34 cervical SCC patients who received NACT before surgery were shown in Table 3 . A matched pair of tissue samples from the same patient prior to chemotherapy and after chemotherapy was collected from all the 34 patients. Each sample was divided into two parts: one part was put into liquid nitrogen within 10 minutes after separation, and then stored at $-80^{\circ} \mathrm{C}$, and the other part was used for pathological diagnosis after hematoxylin-eosin (HE) staining. The ages of cervical SCC patients with chemotherapy ranged from 32 to 67 years old, with a mean age of 47.5 years old.

The informed consents were obtained from all patients, and the study was approved by the ethics committee of Xinjiang Medical University. Female patients with other malignant tumors, gestation, breast-feeding, or complications who were intolerant to chemotherapy were excluded. Clinical staging was performed according to the 2009 International Federation of Gynecology and Obstetrics (FIGO) staging criteria, and the images were read by two pathology experts independently based on the WHO histopathological criteria.

\section{Reagents}

RNeasy FFPE Kit (cat. no. 73504) was purchased from QIAGEN Ltd (Hilden, Germany). Trizol was obtained from Invitrogen CO., Ltd. (Carlsbad, California, USA). Reverse transcription Kit (\#K1622) and real-time fluorescent quantitative PCR Mix (\#K0221) were purchased from Thermo Fisher Scientific Inc (Vilnius, Lithuania). 
Table 1 Clinical pathological data of cervical SCC patients $(n=77)$

\begin{tabular}{|c|c|c|c|c|c|c|c|c|}
\hline $\begin{array}{l}\text { Cervical } \\
\text { SCC } \\
\text { patients }\end{array}$ & $\begin{array}{l}\text { Age } \\
\text { (year) }\end{array}$ & $\begin{array}{l}\text { Selection } \\
\text { date }\end{array}$ & $\begin{array}{l}\text { Clinical } \\
\text { stage }\end{array}$ & Differentai-ation degree & $\begin{array}{l}\text { Lymph } \\
\text { node } \\
\text { metastasis }\end{array}$ & $\begin{array}{l}\text { Tumor } \\
\text { size } \\
(\mathrm{cm})\end{array}$ & LVSI & HPV infection \\
\hline 1 & 46 & 2010.7 .2 & Stage I & Well differentiation & No & $\leq 4$ & No & Single/multiple HPV16 infection \\
\hline 2 & 44 & 2010.7 .5 & Stage ॥ & Moderate and poor differentiation & No & $\leq 4$ & No & Single/multiple HPV16 infection \\
\hline 3 & 35 & 2010.7.13 & Stage I & Well differentiation & No & $\leq 4$ & Yes & Negative \\
\hline 4 & 39 & 2010.7.26 & Stage ॥ & Moderate and poor differentiation & No & $\leq 4$ & No & Negative \\
\hline 5 & 38 & 2010.7.30 & Stage I & Moderate and poor differentiation & Yes & $>4$ & No & Other HPV type \\
\hline 6 & 30 & 2010.8.2 & Stage I & Moderate and poor differentiation & No & $\leq 4$ & No & Single/multiple HPV16 infection \\
\hline 7 & 47 & 2010.8 .5 & Stage III-IV & Well differentiation & Yes & $\leq 4$ & No & Single/multiple HPV16 infection \\
\hline 8 & 41 & 2010.8.12 & Stage ॥ & Well differentiation & No & $>4$ & No & Single/multiple HPV16 infection \\
\hline 9 & 44 & 2010.8.23 & Stage ॥ & Moderate and poor differentiation & No & $\leq 4$ & No & Negative \\
\hline 10 & 38 & 2010.8 .23 & Stage III-IV & Moderate and poor differentiation & No & $\leq 4$ & No & Other HPV type \\
\hline 11 & 27 & 2010.8 .25 & Stage III-IV & Well differentiation & No & $\leq 4$ & No & Other HPV type \\
\hline 12 & 48 & 2010.8.30 & Stage I & Moderate and poor differentiation & No & $\leq 4$ & No & Negative \\
\hline 13 & 42 & 2010.9.7 & Stage ॥ & Well differentiation & Yes & $>4$ & Yes & Single/multiple HPV16 infection \\
\hline 14 & 44 & 2010.9.10 & Stage I & Moderate and poor differentiation & No & $\leq 4$ & No & Negative \\
\hline 15 & 42 & 2010.9.17 & Stage I & Moderate and poor differentiation & No & $>4$ & No & Single/multiple HPV16 infection \\
\hline 16 & 45 & 2010.9.27 & Stage ॥ & Moderate and poor differentiation & No & $>4$ & No & Single/multiple HPV16 infection \\
\hline 17 & 44 & 2010.9.28 & Stage ॥ & Moderate and poor differentiation & No & 1 & No & Single/multiple HPV16 infection \\
\hline 18 & 42 & 2010.9.28 & Stage $\|$ & Moderate and poor differentiation & No & $\leq 4$ & No & Other HPV type \\
\hline 19 & 47 & 2010.9.30 & Stage ॥ & Moderate and poor differentiation & Yes & $>4$ & No & Single/multiple HPV16 infection \\
\hline 20 & 39 & 2010.10.18 & Stage I & Moderate and poor differentiation & No & $\leq 4$ & No & Single/multiple HPV16 infection \\
\hline 21 & 48 & 2010.10 .28 & Stage ॥ & Well differentiation & No & $\leq 4$ & No & Single/multiple HPV16 infection \\
\hline 22 & 36 & 2010.11 .2 & Stage ॥ & Moderate and poor differentiation & Yes & $>4$ & Yes & Other HPV type \\
\hline 23 & 43 & 2010.11 .16 & Stage ॥ & Moderate and poor differentiation & No & $\leq 4$ & No & Other HPV type \\
\hline 24 & 34 & 2010.11 .24 & Stage I & Moderate and poor differentiation & No & $\leq 4$ & No & Other HPV type \\
\hline 25 & 46 & 2010.12 .10 & Stage III-IV & Well differentiation & - & $>4$ & - & Other HPV type \\
\hline 26 & 45 & 2010.12.16 & Stage ॥ & Well differentiation & - & $\leq 4$ & - & Other HPV type \\
\hline 27 & 32 & 2010.12.27 & Stage III-IV & Well differentiation & - & $\leq 4$ & - & Single/multiple HPV16 infection \\
\hline 28 & 27 & 2011.1.7 & Stage III-IV & Well differentiation & - & $>4$ & - & Single/multiple HPV16 infection \\
\hline 29 & 40 & 2011.1.14 & Stage III-IV & Well differentiation & - & $\leq 4$ & - & Single/multiple HPV16 infection \\
\hline 30 & 29 & 2011.1.17 & Stage III-IV & Well differentiation & - & $\leq 4$ & - & Other HPV type \\
\hline 31 & 42 & 2011.2 .21 & Stage I & Well differentiation & - & $\leq 4$ & - & Single/multiple HPV16 infection \\
\hline 32 & 35 & 2011.2 .25 & Stage I & Well differentiation & - & $\leq 4$ & - & Negative \\
\hline 33 & 29 & 2011.3.1 & Stage III-IV & Well differentiation & - & $>4$ & - & Negative \\
\hline 34 & 38 & 2011.3.10 & Stage III-IV & Well differentiation & - & $\leq 4$ & - & Other HPV type \\
\hline 35 & 41 & 2011.3.15 & Stage III-IV & Well differentiation & - & $\leq 4$ & - & Single/multiple HPV16 infection \\
\hline 36 & 28 & 2011.3.19 & Stage ॥ & Moderate and poor differentiation & - & $\leq 4$ & - & Single/multiple HPV16 infection \\
\hline 37 & 40 & 2011.3.21 & Stage ॥ & Moderate and poor differentiation & - & $>4$ & - & Negative \\
\hline 38 & 37 & 2011.4 .9 & Stage \| & Moderate and poor differentiation & - & $\leq 4$ & - & Other HPV type \\
\hline 39 & 43 & 2011.4 .13 & Stage ॥ & Moderate and poor differentiation & - & $>4$ & - & Single/multiple HPV16 infection \\
\hline 40 & 29 & 2011.4.18 & Stage ॥ & Well differentiation & - & $>4$ & - & Other HPV type \\
\hline 41 & 43 & 2011.4.21 & Stage II & Moderate and poor differentiation & - & $>4$ & - & Single/multiple HPV16 infection \\
\hline 42 & 53 & 2011.4.22 & Stage III-IV & Moderate and poor differentiation & No & $>4$ & Yes & Negative \\
\hline 43 & 66 & 2011.5.10 & Stage III-IV & Moderate and poor differentiation & No & $\leq 4$ & No & Other HPV type \\
\hline
\end{tabular}


Table 1 Clinical pathological data of cervical SCC patients $(\mathbf{n}=\mathbf{7 7})$ (Continued)

\begin{tabular}{|c|c|c|c|c|c|c|c|c|}
\hline 44 & 54 & 2011.5.16 & Stage III-IV & Moderate and poor differentiation & No & $\leq 4$ & No & Other HPV type \\
\hline 45 & 56 & 2011.5.23 & Stage II & Moderate and poor differentiation & No & $\leq 4$ & No & Other HPV type \\
\hline 46 & 57 & 2011.5 .25 & Stage II & Moderate and poor differentiation & Yes & $\leq 4$ & Yes & Other HPV type \\
\hline 47 & 54 & 2011.5 .30 & Stage II & Well differentiation & No & $\leq 4$ & No & Other HPV type \\
\hline 48 & 54 & 2011.6 .3 & Stage III-IV & Moderate and poor differentiation & Yes & $\leq 4$ & No & Other HPV type \\
\hline 49 & 66 & 2011.6 .10 & Stage II & Moderate and poor differentiation & Yes & $\leq 4$ & No & Other HPV type \\
\hline 50 & 77 & 2011.6 .14 & Stage III-IV & Moderate and poor differentiation & Yes & $\leq 4$ & No & Single/multiple HPV16 infection \\
\hline 51 & 50 & 2011.6 .15 & Stage II & Well differentiation & No & $\leq 4$ & No & Single/multiple HPV16 infection \\
\hline 52 & 68 & 2011.6 .20 & Stage II & Well differentiation & No & $\leq 4$ & No & Negative \\
\hline 53 & 61 & 2011.7.11 & Stage II & Moderate and poor differentiation & No & $\leq 4$ & Yes & Negative \\
\hline 54 & 69 & 2011.7 .15 & Stage II & Moderate and poor differentiation & No & $\leq 4$ & Yes & Other HPV type \\
\hline 55 & 49 & 2011.7 .18 & Stage II & Moderate and poor differentiation & No & $>4$ & No & Single/multiple HPV16 infection \\
\hline 56 & 49 & 2011.7 .18 & Stage II & Moderate and poor differentiation & Yes & $>4$ & Yes & Negative \\
\hline 57 & 54 & 2011.8 .1 & Stage II & Moderate and poor differentiation & No & $\leq 4$ & No & Single/multiple HPV16 infection \\
\hline 58 & 51 & 2011.8 .25 & Stage III-IV & Well differentiation & No & $\leq 4$ & No & Single/multiple HPV16 infection \\
\hline 59 & 56 & 2011.8 .26 & Stage II & Moderate and poor differentiation & Yes & $\leq 4$ & Yes & Single/multiple HPV16 infection \\
\hline 60 & 53 & 2011.913 & Stage II & Moderate and poor differentiation & No & $>4$ & No & Single/multiple HPV16 infection \\
\hline 61 & 50 & 2011.9 .16 & Stage I & Well differentiation & No & $\leq 4$ & No & Other HPV type \\
\hline 62 & 51 & 2011.9.21 & Stage II & Moderate and poor differentiation & No & $\leq 4$ & No & Single/multiple HPV16 infection \\
\hline 63 & 49 & 2011.9 .23 & Stage I & Well differentiation & No & $\leq 4$ & No & Negative \\
\hline 64 & 57 & 2011.10 .14 & Stage II & Moderate and poor differentiation & No & $\leq 4$ & Yes & Negative \\
\hline 65 & 61 & 2011.11 .2 & Stage II & Well differentiation & No & $>4$ & No & Other HPV type \\
\hline 66 & 52 & 2011.11 .15 & Stage II & Moderate and poor differentiation & No & $\leq 4$ & No & Negative \\
\hline 67 & 50 & 2011.11 .17 & Stage II & Moderate and poor differentiation & Yes & $>4$ & No & Single/multiple HPV16 infection \\
\hline 68 & 56 & 2011.11 .21 & Stage I & Moderate and poor differentiation & No & $\leq 4$ & Yes & Negative \\
\hline 69 & 64 & 2011.11 .25 & Stage I & Moderate and poor differentiation & No & $\leq 4$ & No & Single/multiple HPV16 infection \\
\hline 70 & 80 & 2011.12 .2 & Stage II & Moderate and poor differentiation & No & $\leq 4$ & Yes & Single/multiple HPV16 infection \\
\hline 71 & 61 & 2011.12 .2 & Stage II & Well differentiation & Yes & $\leq 4$ & No & Other HPV type \\
\hline 72 & 49 & 2011.12 .5 & Stage II & Moderate and poor differentiation & No & $>4$ & No & Other HPV type \\
\hline 73 & 49 & 2011.12 .16 & Stage II & Moderate and poor differentiation & Yes & $\leq 4$ & No & Other HPV type \\
\hline 74 & 59 & 2012.1.10 & Stage II & Moderate and poor differentiation & Yes & $\leq 4$ & No & Other HPV type \\
\hline 75 & 50 & 2012.1.13 & Stage II & Moderate and poor differentiation & Yes & $>4$ & No & Single/multiple HPV16 infection \\
\hline 76 & 67 & 2012.1.16 & Stage I & Moderate and poor differentiation & No & $\leq 4$ & Yes & Other HPV type \\
\hline 77 & 58 & 2012.1.19 & Stage III-IV & Moderate and poor differentiation & - & $\leq 4$ & - & Negative \\
\hline
\end{tabular}

Note: SCC, squamous cell carcinoma; LVSI, lymph vascular space invasion. "-" indicates that no such examination was performed. Among the 77 cervical patients, 59 cases received extensive hysterectomy and pelvic lymphadenectomy and 18 cases were not treated with surgery. Lymph node metastasis and LVSI were not examined in these 18 cases who were not treated with surgery.

The specific reverse transcriptase and PCR primers of U6 and miR-143 were synthesized by Taihe Biotechnology Co., Ltd. (Beijing, China). The bcl-2 antibody (sc7382) was purchased from Santa Cruz Biotechnology Inc (California, USA). The universal secondary antibody (PV-6000), goat serum and diaminobenzidine (DAB) reagent were all purchased from Beijing Zhong ShanGolden Bridge Biological Technology CO., Ltd. (Beijing, China). Cell lysis buffer and the HPV genotype detection kit were products from Chaozhou Kaipu Biochemistry
Co. Ltd. (Chaozhou, China). ABI7500 real-time PCR system was purchased from Applied Biosystems, Inc. (New York, USA), and the OLYMPUS microscopy was from Olympus optical Co., Ltd. (Tokyo, Japan).

\section{HPV genotype detection}

Exfoliated cervical cell specimens were obtained by cervical brush clockwise rotation for five turns at the cervix. DNA was extracted from these specimens for determination of HPV genotypes. For DNA amplication, $1 \mu \mathrm{l}$ of 
Table $\mathbf{2}$ Clinical data of $\mathbf{2 0}$ control patients with normal cervixes $(\mathbf{n}=20)$

\begin{tabular}{llllll}
\hline Patients & $\begin{array}{l}\text { Age } \\
\text { (year) }\end{array}$ & $\begin{array}{l}\text { Selection } \\
\text { date }\end{array}$ & Patients & $\begin{array}{l}\text { Age } \\
\text { (year) }\end{array}$ & $\begin{array}{l}\text { Selection } \\
\text { date }\end{array}$ \\
\hline 1 & 43 & 2010.7 .14 & 11 & 42 & 2011.5 .13 \\
2 & 32 & 2010.7 .29 & 12 & 40 & 2011.6 .16 \\
3 & 50 & 2010.8 .13 & 13 & 39 & 2011.7 .15 \\
4 & 30 & 2010.9 .15 & 14 & 44 & 2011.8 .16 \\
5 & 37 & 2010.9 .16 & 15 & 66 & 2011.9 .13 \\
6 & 41 & 2010.10 .19 & 16 & 31 & 2011.9 .16 \\
7 & 40 & 2010.12 .17 & 17 & 45 & 2011.10 .18 \\
8 & 47 & 2011.1 .17 & 18 & 76 & 2011.11 .21 \\
9 & 59 & 2011.3 .17 & 19 & 42 & 2011.12 .2 \\
10 & 63 & 2011.4 .20 & 20 & 50 & 2012.1 .10 \\
\hline
\end{tabular}

DNA and $24 \mu \mathrm{l}$ of HPV PCR reaction solution (containing Taq polymerase, dNTP and primers) were mixed together to form a $25 \mu \mathrm{l}$ system. Then PCR products were hybridized to films according to the manufacturer's instruction. During the color development, $0.5 \mathrm{ml}$ of alkaline phosphatase chromogenic substrates were added and incubated for $2-5$ minutes at $36^{\circ} \mathrm{C}$. Results were analyzed within 1 hour after color development through visual observation. Positive points were defined as clear visible blue purple dots. There were one PCR reaction control and one hybridization coloration quality control point on each film. The HPV genotypes were determined based on their distribution sites on the films, including $21 \mathrm{HPV}$ genotypes of $6,11,16,18,31,33,35,39,42,43$, $44,45,51,52,53,56,58,59,66,68$ and 81 (CP8304).

\section{Reverse transcription and real-time PCR}

Total RNAs of paraffin-embedded cervical tissues were extracted according to the RNeasy FFPE kit's instruction, while those of the fresh cervical tissues were extracted by Trizol. U6 was used as internal standard control. The volume of reverse transcription reaction system was $20 \mu \mathrm{l}$, containing $200 \mathrm{ng}$ of total RNAs, $1 \mu \mathrm{l}$ of reverse transcription primers diluted to $12 \mu \mathrm{l}$ with water, $4 \mu \mathrm{l}$ of buffer, $1 \mu \mathrm{l}$ of RNase inhibitor, $2 \mu \mathrm{l}$ of dNTP and $1 \mu \mathrm{l}$ of $\mathrm{M}-\mathrm{MuLV}$ reverse transcriptase. Reverse transcriptions were performed. The miR-143-specific primer sequence for reverse transcription was: 5'-GTCGTATCCAGTGC GTGTCGTGGAGTCGGCAATTGCACTGGATACGAC TGAGCTA-3'. The miR-143-specific PCR primer sequences for real-time PCR were: forward, 5'-AGTGCGTG TCGTGGAGT-3'; reverse, 5'-GCCTGAGATGAAGCAC TGT-3'. The U6 PCR primer sequences were: forward, 5'CTCGCTTCGGCAGCACA-3'; reverse, 5'-ACGCTTCA CGAATTTTGCGT-3'.

Each sample was repeated 3 times. The PCR products were analyzed by $2.5 \%$ agarose gel electrophoresis. The
Table 3 Clinical data of 34 cervical SCC patients who received NACT before surgery $(n=34)$

\begin{tabular}{|c|c|c|c|c|}
\hline Patients & Age (year) & Selection date & Clinical stage & NACT efficacy \\
\hline 1 & 45 & 2012.1 .27 & Stage $I_{b 2}$ & Effective \\
\hline 2 & 34 & 2012.2 .4 & Stage Ila & Effective \\
\hline 3 & 36 & 2012.3.12 & Stage $\| \mathrm{b}$ & Effective \\
\hline 4 & 47 & 2012.4 .15 & Stage $I_{b 2}$ & Not effective \\
\hline 5 & 57 & 2012.4 .17 & Stage $I_{b 2}$ & Effective \\
\hline 6 & 39 & 2012.5 .15 & Stage Ila & Effective \\
\hline 7 & 45 & 2012.5 .18 & Stage lla & Effective \\
\hline 8 & 42 & 2012.6 .3 & Stage IIb & Not effective \\
\hline 9 & 32 & 2012.6.17 & Stage $I_{b 2}$ & Effective \\
\hline 10 & 66 & 2012.6 .26 & Stage Ila & Not effective \\
\hline 11 & 59 & 2012.7.14 & Stage $\| \mathrm{b}$ & Not effective \\
\hline 12 & 46 & 2012.8 .4 & Stage $I_{b 2}$ & Effective \\
\hline 13 & 49 & 2012.8 .15 & Stage Ila & Not effective \\
\hline 14 & 51 & 2012.8.24 & Stage $I_{b 2}$ & Effective \\
\hline 15 & 35 & 2012.8 .29 & Stage $I_{b 2}$ & Effective \\
\hline 16 & 38 & 2012.9.16 & Stage Ila & Not effective \\
\hline 17 & 40 & 2012.9.19 & Stage $I_{b 2}$ & Effective \\
\hline 18 & 43 & 2012.10 .7 & Stage Ila & Effective \\
\hline 19 & 58 & 2012.10 .11 & Stage Ilb & Effective \\
\hline 20 & 63 & 2012.10 .17 & Stage Ila & Not effective \\
\hline 21 & 53 & 2012.10 .19 & Stage $I_{b 2}$ & Effective \\
\hline 22 & 48 & 2012.10 .25 & Stage $I_{b 2}$ & Effective \\
\hline 23 & 43 & 2012.10 .28 & Stage Ila & Effective \\
\hline 24 & 45 & 2012.11 .1 & Stage Illb & Not effective \\
\hline 25 & 44 & 2012.11 .5 & Stage Ila & Effective \\
\hline 26 & 61 & 2012.11 .16 & Stage $I_{b 2}$ & Not effective \\
\hline 27 & 39 & 2012.11 .23 & Stage lla & Effective \\
\hline 28 & 67 & 2012.11 .25 & Stage Ila & Effective \\
\hline 29 & 56 & 2012.11 .30 & Stage $I_{b 2}$ & Effective \\
\hline 30 & 44 & 2012.12 .2 & Stage $I_{b 2}$ & Effective \\
\hline 31 & 33 & 2012.12 .10 & Stage Ila & Not effective \\
\hline 32 & 54 & 2012.12 .15 & Stage $I_{b 2}$ & Effective \\
\hline 33 & 57 & 2012.12.19 & Stage lla & Effective \\
\hline 34 & 49 & 2012.12 .22 & Stage $I_{b 2}$ & Effective \\
\hline
\end{tabular}

Note: SCC, squamous cell carcinoma. NACT, neoadjuvant chemotherapy.

number of cycles for each reaction tube to reach the preestablished fluorescence threshold was recorded as $\mathrm{Ct}$ value, and the relative expression quantities of miR-143 were presented as $\mathrm{N}=2^{-\Delta \Delta \mathrm{Ct}}$. For the comparison of cervical SCC group to normal cervix group, $\Delta \Delta \mathrm{Ct}=\left(\mathrm{Ct}_{\text {miR-143- }}\right.$ $\left.\mathrm{Ct}_{\mathrm{U} 6}\right)_{\mathrm{SCC}}$ - (average $\mathrm{Ct}_{\mathrm{miR}-143}$ - average $\left.\mathrm{Ct}_{\mathrm{U} 6}\right)_{\text {normal; }}$; For the comparison of cervical SCC group after chemotherapy to the cervical SCC group before chemotherapy, $\Delta \Delta \mathrm{Ct}=$ $\left(\mathrm{Ct}_{\mathrm{miR}-143}-\mathrm{Ct}_{\mathrm{U} 6}\right)_{\text {after }}-\left(\mathrm{Ct}_{\mathrm{miR}-143}-\mathrm{Ct}_{\mathrm{U} 6}\right)_{\text {before }}$. 


\section{Immunohistochemistry}

Immunohistochemistry was performed in fresh cervical tissues to detect the expression of Bcl-2. Briefly, slices (4 $\mu \mathrm{m}$ in thickness) were incubated in $3 \% \mathrm{H}_{2} \mathrm{O}_{2}$ for 10 minutes at room temperature to block endogenous peroxidase. Bcl-2 mouse monoclonal antibody (1:200) was added and kept at $4^{\circ} \mathrm{C}$ overnight, and then incubated for 1 hour at room temperature. Then, the universal IgG antibody conjugated with HRP was added and incubated at $37^{\circ} \mathrm{C}$ for 25 minutes. DAB solution was used for color development, and the staining results were observed under microscopy. Finally, the slices were counterstained with hematoxylin for 10 minutes, differentiated with hydrochloric acid ethanol, and then mounted with neutral gum after dehydration. The slices were observed under microscopy. Bcl-2 positive breast cancer tissue was used as bcl-2 positive control and PBS instead of the primary antibody was used as negative control. Positive staining cells were stained brownyellow or yellow in the cytoplasm or cell membrane. Five fields were randomly selected on each slice and 200 cells were counted in each field. Then the percentage of positive cells in all counted cells was calculated. Negative staining was defined as no positive staining on the whole slice or the percentage of positive cells $<10 \%$ and positive staining was defined as the percentage of positive cells $>10 \%$.

\section{NACT}

The chemotherapy regimen included Taxol $\left(175 \mathrm{mg} / \mathrm{m}^{2}\right)$ and carboplatin (dosage of which was calculated based on the age, serum creatinine and weight of the patient). Taxol and carboplatin were administered within one day. Two courses of treatments were taken with an interval of 3 weeks, and surgery was performed $2-3$ weeks after the chemotherapy. The tumor sizes of the patients treated with NACT were measured through gynecological and imaging examinations before chemotherapy, and measured by pathological examinations after surgery. According to the WHO criteria, effectiveness of treatment was defined as the follows: complete remission, tumor is completely disappeared; partial remission, the tumor size decreases more than $50 \%$; stable or no change, the tumor size increases or decreases no more than $25 \%$, and no new lesions appear; progression, new lesions appear or the size of tumor increases more than $25 \%$ during the treatment. Complete and partial remissions were defined as effective.

\section{Statistical analysis}

Data were processed using SPSS 17.0 software. The data was non-normal distribution and thus median and quartile were used. Mann-Whitney U test was used for comparison between two groups, while Kruskal-Wallis $\mathrm{H}$ test was used for comparison among multiple groups. $\mathrm{P}<0.05$ was considered as statistically significant.

\section{Results}

The miR-143 expression in normal cervix and cervical SCC tissues and its correlation with clinical pathological

\section{features of cervical SCC}

To determine the expression levels of miR-143 in normal cervix and cervical SCC, real time PCR was performed. Quantitative results of miR-143 expression and its correlation with clinical pathological features of cervical SCC were shown in Figure 1 and Table 4. In comparison with normal cervix, the expression level of miR-143 in cervical SCC group was decreased, and the difference was statistically significant $(\mathrm{Z}=-2.180, \mathrm{P}=$ 0.029). The expression of miR-143 in cervical SCC with tumor diameter $\leq 4 \mathrm{~cm}$ was significantly higher than that with tumor diameter $>4 \quad \mathrm{~cm} \quad(\mathrm{Z}=-2.705, \quad \mathrm{P}=0.007)$ (Table 4 and Figure 1A). And, miR-143 expression level
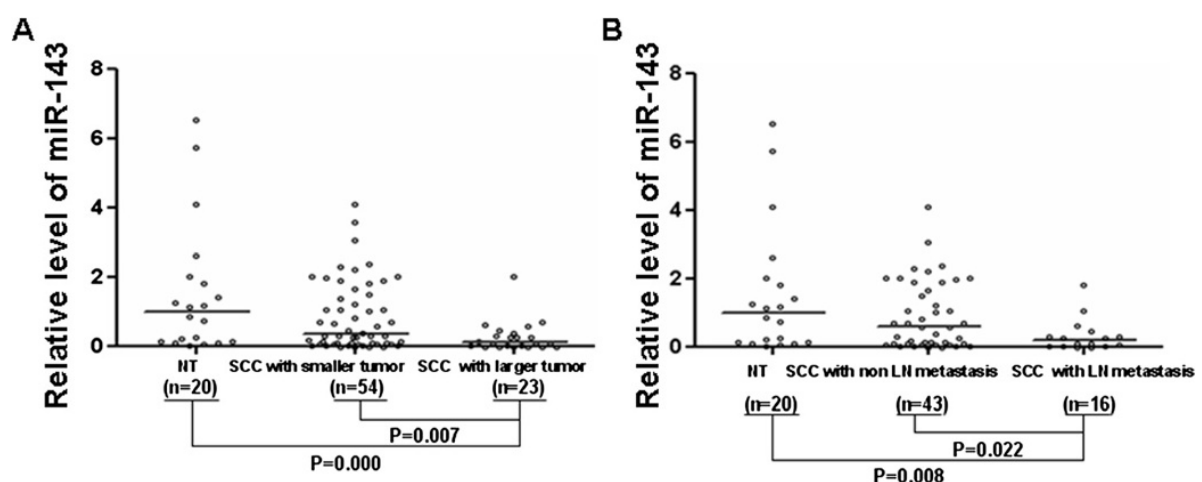

Figure 1 Comparison of miR-143 expression in normal cervical tissue and cervical SCC tissue with different tumor size and lymph node metastasis. Real time PCR was conducted to detect miR-143 expression. Relative expression of miR-143 was calculated using the $2^{-\Delta \Delta C t}$ method. (A) Comparison of miR-143 expression in normal cervical tissue (NT) and cervical SCC tissue with smaller tumor (tumor diameter $\leq 4 \mathrm{~cm}$ ) and larger tumor (tumor diameter $>4 \mathrm{~cm}$ ). (B) Comparison of miR-143 expression in normal cervical tissue (NT) and cervical SCC tissue with or without lymph node (LN) metastasis. 
Table 4 Correlation between miR-143 expression and cervical SCC clinical pathological features

\begin{tabular}{|c|c|c|c|c|}
\hline Clinical characters & $\begin{array}{l}\text { Cases } \\
\text { (n) }\end{array}$ & miR-143 expression & Z & $P$ \\
\hline Cervical SCC & & & -2.180 & $\overline{0.029^{*}}$ \\
\hline No & 20 & $1.000(0.241-1.878)$ & & \\
\hline Yes & 77 & $0.280(0.059-1.050)$ & & \\
\hline Age (years old) & & & -1.236 & 0.217 \\
\hline$\leq 50$ & 41 & $0.259(0.143-0.707)$ & & \\
\hline$>50$ & 36 & $0.337(0.167-1.092)$ & & \\
\hline Clinical Stage & & & 2.673 & 0.263 \\
\hline । & 16 & $0.387(0.176-1.258)$ & & \\
\hline$\|$ & 43 & $0.268(0.131-0.698)$ & & \\
\hline III-IV & 18 & $0.287(0.155-0.905)$ & & \\
\hline Pathological Grade & & & -1.142 & 0.253 \\
\hline Well differentiation & 27 & $0.320(0.198-0.859)$ & & \\
\hline $\begin{array}{l}\text { Moderate and poor } \\
\text { differentiation }\end{array}$ & 50 & $0.258(0.118-1.052)$ & & \\
\hline Lymph node metastasis & & & -2.293 & $0.022^{*}$ \\
\hline No & 43 & $0.578(0.209-1.384)$ & & \\
\hline Yes & 16 & $0.175(0.103-0.544)$ & & \\
\hline Tumor diameter & & & -2.705 & $0.007^{*}$ \\
\hline$\leq 4 \mathrm{~cm}$ (smaller tumor) & 54 & $0.345(0.112-1.490)$ & & \\
\hline$>4$ cm (larger tumor) & 23 & $0.125(0.103-0.459)$ & & \\
\hline LVSI & & & -0.567 & 0.571 \\
\hline No & 46 & $0.294(0.159-1.075)$ & & \\
\hline Yes & 13 & $0.607(0.293-1.501)$ & & \\
\hline HPV infection & & & 9.050 & $0.011^{*}$ \\
\hline HPV negative & 17 & $1.053(0.289-1.412)$ & & \\
\hline $\begin{array}{l}\text { HPV16 infection } \\
\text { (single or multiple) }^{\triangle}\end{array}$ & 32 & $0.230(0.105-0.496)$ & -2.647 & $0.008^{*}$ \\
\hline $\begin{array}{l}\text { Other genotype } \\
\text { HPV infection }\end{array}$ & 28 & $0.524(0.109-1.233)$ & -1.651 & 0.099 \\
\hline
\end{tabular}

Note: *P $<0.05 .{ }^{\triangle}$ in comparison with HPV negative group.

SCC, squamous cell carcinoma; LVSI, lymph vascular space invasion.

in cervical SCC without lymph node metastasis was higher than that with lymph node metastasis and the difference was also statistically significant $(\mathrm{Z}=-2.293, \mathrm{P}=$ 0.022) (Table 4 and Figure 1B).

In addition, the HPV genotype was detected. In cervical SCC patients, there were $60 \mathrm{HPV}$ positive patients (78\%). Among them, 32 were infected by HPV16 (42\%), including 25 single infections (33\%) and 7 mixed infections $(9 \%)$, and 28 patients were infected by other HPV genotypes, in which HPV18, HPV52 and HPV58 were the major genotypes. Statistically, the expression of miR143 in HPV negative cervical SCC patients was significantly higher than that in HPV positive cervical SCC patients $(Z=9.050, P=0.011)$ (Table 4). Meanwhile, in comparison with HPV negative cervical SCC patients, the expression of miR-143 in the HPV16 positive cervical SCC patients was significantly lower $(Z=-2.647$, $\mathrm{P}=0.008$ ) whereas in cervical SCC patients infected with other HPV genotypes, the difference was not significant $(\mathrm{Z}=-1.651, \mathrm{P}=0.099)$. However, the miR-143 expression levels between ages, clinical stages, pathological grades and LVSI were not significantly different.

Collectively, these data suggest that miR-143 expression in cervical SCC patients was down-regulated and that it was significantly correlated with lymph node metastasis, tumor diameter and HPV infection, but not with ages, clinical stages, pathological grades or LVSI.

\section{Evaluation of miR-143 expression as predictor of tumor size and lymph node metastasis}

The specificity and sensitivity of miR-143 evaluation on tumor size and lymph node metastasis of cervical SCC were analyzed by receiver operating characteristic (ROC) curve (Figure 2). Tumor size with tumor diameter $>$ $4 \mathrm{~cm}$ was defined as larger tumor and $\leq 4 \mathrm{~cm}$ as smaller tumor. As shown in Figure 2A, the AUC of miR-143 to differentiate larger tumor from smaller tumor was 0.696 (95\% confidence interval: $0.573-0.818, \mathrm{P}=0.007$ ). If the relative expression level of 0.286 was used as the evaluation critical value, the sensitivity and specificity of miR143 to differentiate tumor size were $70.5 \%$ and $61.0 \%$, respectively. As shown in Figure $2 \mathrm{~B}$, the AUC of miR143 to evaluate whether there was lymph node metastasis was 0.690 ( $95 \%$ confidence interval: $0.555-0.836$, $\mathrm{P}=0.022$ ). If the relative expression value of 0.314 was used as the evaluation critical value, the sensitivity and specificity of miR-143 to differentiate whether there was lymph node metastasis were $75.0 \%$ and $60.0 \%$, respectively. Thus miR-143 may be used as an indicator for the evaluation of tumor size and lymph node metastasis of cervical SCC, with good specificity and sensitivity.

\section{Expression of miR-143 and its target gene bcl-2 in cervical SCC before and after NACT}

As mentioned in the Materials and methods, Taxol was used in NACT. To investigate whether miR-143 participated in the Taxol sensitivity response, we further analyzed expression of miR-143 and its target gene bcl-2 in cervical SCC patients underwent NACT before surgery. For the 34 patients who underwent chemotherapy before surgery, 5 cases were with complete remissions, 19 cases were with partial remissions. And the effective rate of chemotherapy was $70.83 \%$ (24/34). The expression of miR-143 before and after NACT was analyzed by real time PCR in 24 patients who were treated effectively. The same tissues without chemotherapy were used as control. Expression of miR-143 was up-regulated after NACT treatment, with the relative expression level of 1.35 (0.44 - 4.29). However, there was no statistical 

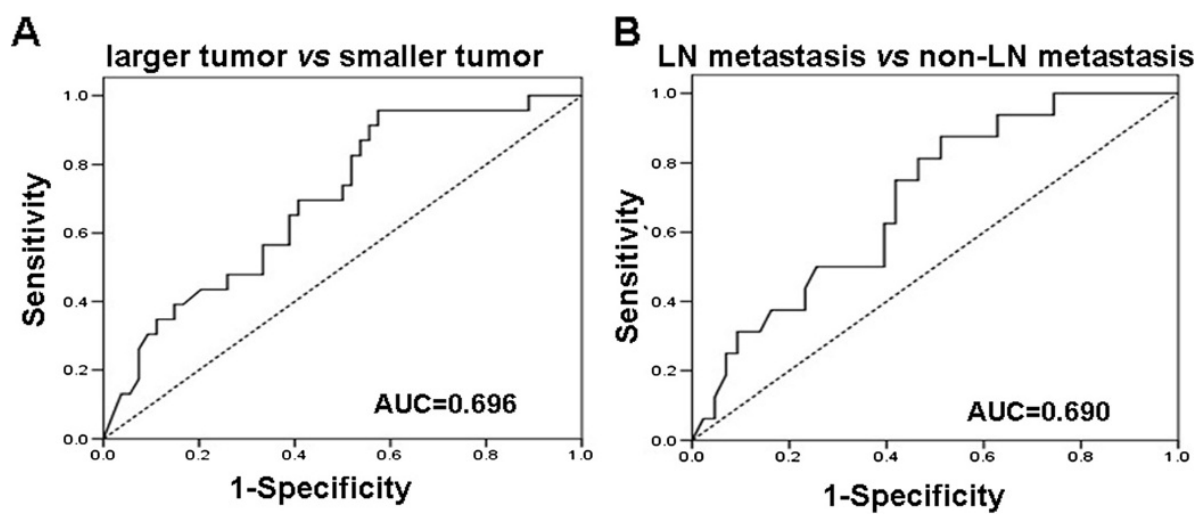

Figure 2 Analysis of miR-143 expression in cervical SCC patients by ROC curve. (A) ROC curve of miR-143 expression in cervical SCC patients with different tumor diameter. Tumor size with tumor diameter $>4 \mathrm{~cm}$ was defined as larger tumor and $\leq 4 \mathrm{~cm}$ as smaller tumor. (B) ROC curve of miR-143 expression in cervical SCC patients with and without lymph node (LN) metastasis.

significance in expression level of miR-143 before and after NACT $(Z=-0.763, P=0.446)$ (Figure 3$)$.

The expression of bcl-2 protein before and after NACT was also analyzed in effective patients with immunohistochemistry. Representative immunohistochemical results were shown in Figure 4. Figure 4A and B showed the positive expression of bcl-2 in fresh cervical tissues before NACT treatment and after NACT treatment. Bcl-2 positive cells were stained brown-yellow or yellow in the cytoplasm or cell membrane. Bcl-2 positive cells were counted and positive expression rate of bcl-2 was calculated. A percentage of bcl-2 positive cells $>10 \%$ was defined as positive bcl- 2 expression. Statistically, the positive expression rate of bcl-2 was $75 \%$ (18/24) before NACT and $54.17 \%(13 / 24)$ after NACT, however, the difference was not statistically significant $\left(X^{2}=2.277\right.$, $\mathrm{P}=0.131$ ) (data not shown).
Thus miR-143 and bcl-2 expression was not significantly changed before and after NACT therapy, suggesting that they may not participate in the Taxol sensitivity response.

\section{Discussion}

Some studies indicate that miR-143 is up-regulated in tumor tissues [10,11]. Also, through inhibition of FNDC3B, miR-143 promotes the metastasis of hepatic carcinoma (animal study) to the lung and the metastasis of prostate cancer cells $[12,13]$. However, most of the studies demonstrate that miR-143 is down-regulated in solid tumor, including esophageal cancer, bladder cancer and prostate cancer, etc. [14-16]. The target genes of miR143 include KRAS, MACC1 and bcl-2, etc. [17-19], which are involved in the signaling pathways of ERK5 and MAPK, etc. [20,21]. Among those target genes, bcl-2 is an

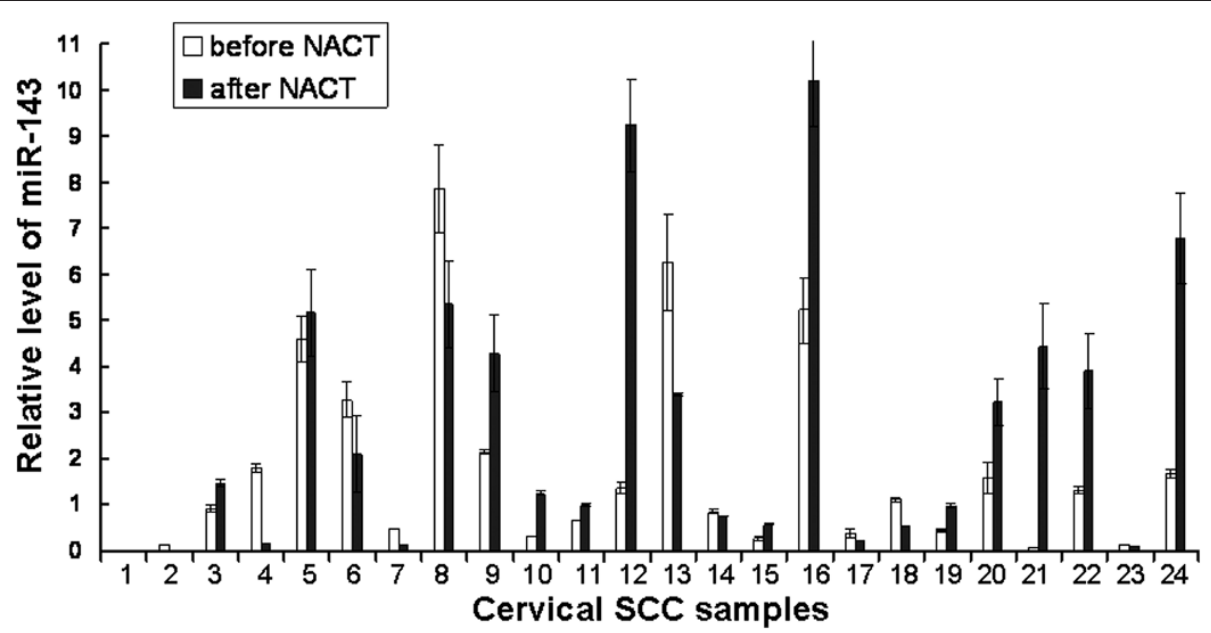

Figure 3 Comparison of the relative miR-143 expression level in cervical SCC tissues before and after neoadjuvant chemotherapy (NACT). Cervical SCC tissues were collected from 24 cervical SCC patients with effective NACT. Real time PCR was performed to detect miR-143 expression before and after NACT. Relative expression of miR-143 was calculated using the $2^{-\Delta \Delta C t}$ method. 


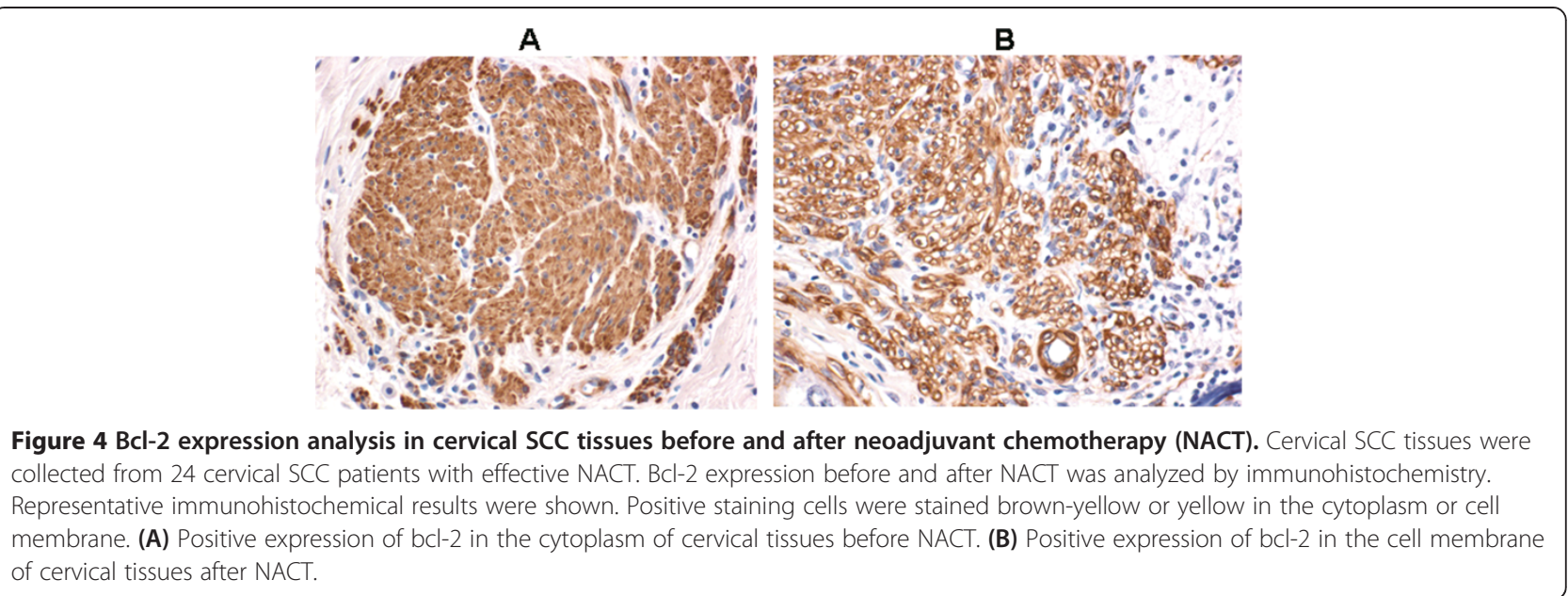

oncogene involved in cell apoptosis. The function of bcl-2 protein is to inhibit apoptosis by providing cell resistance to multiple apoptosis-stimulating factors. It is reported that through targeting bcl-2, miR-181d inhibited neuroglia cell proliferation and promoted apoptosis [22] while miR$15 \mathrm{~b}$ and miR-16 played a role in the drug resistance of gastric cancer [23].

Our results indicate that miR-143 was significantly down-regulated in cervical SCC, which was consistent with previous reports [24,25]. They both found that miR-143 expression was down-regulated in cervical cancer cell lines and tissues. However, the relationship between miR-143 expression and clinical pathological features of cervical cancer is rarely studied. In this study, we also analyzed whether miR-143 expression was related with clinical pathological features of cervical cancer. Our results showed that the expression of miR-143 was related to the lymph node metastasis of cervical SCC. Expression of miR-143 was significantly lower in patients with lymph node metastasis than that in patients without lymph node metastasis. Similar results were found in esophageal cancer [26], suggesting that down-regulation of miR-143 might promote the lymph node metastasis of cancer cells. The ROC curve analysis showed that the sensitivity and specificity of miR-143 to evaluate lymph node metastasis were $75 \%$ and $60 \%$, respectively. This data suggest that miR-143 may be used as an indicator for lymph node metastasis evaluation in clinic, especially as a reference before surgery. Moreover, our results showed that miR-143 and tumor diameter was negatively correlated. A previous study also showed that the expression of miR-143 in the colorectal cancer tissue with tumor diameter $>5 \mathrm{~cm}$ was lower than that with tumor diameter $<5 \mathrm{~cm}$ [27]. The sensitivity and specificity of miR-143 to evaluate tumor diameter were $70.5 \%$ and $61 \%$, respectively. The self-shedding of exogenous cervical tumor and the underdetermined tumor diameter of endogenous cervical would lower the clinical staging of tumor and influence the individualized treatment of patients. Ivanov et al. reported that in cervical cancer at stage Ib2-IIa, the lymph node metastasis rate and distant metastasis rate were increased as the tumor size enlarged [28], and there was certain correlation between tumor metastasis and tumor size. In addition, we found that the expression of miR-143 was irrelevant to the age, clinical stage, pathological grade and LVSI of the SCC patients.

The infection rate of high-risk HPV in cervical cancer can be up to 50\%-90\% [29]. In this study, there were 60 cases $(78 \%)$ of HPV positive cervical SCC patients, in which there were 32 HPV16 positive cases (42\%). In comparison with the HPV negative cervical SCC patients, miR-143 was significantly down regulated in the HPV16 positive cervical SCC patients, suggesting that this down regulation might be related with the carcinogenic processes of E6 and E7 genes of HPV16. Researches found that there were 53 miRNAs, including miR-143, which were located at the gene fragile sites and near to the HPV integration sites. Of the HPV integration sites, HPV16 integration site was the most important one [30]. The integration of HPV oncogene to the host cell might influence the formation of miR-143 precursor. In addition, E6 gene of HPV16 could inactivate the tumor suppressor p53, which positively regulated the expression of miR-143 by regulating the synthesis of mature miRNAs [31]. It was also reported that E6 gene of HPV16 could down-regulate the expression of miR-128 [32].

The traditional treatment for cervical cancer is surgery and radiotherapy. However, the relapse rate is relatively high and there are many complications in these methods. NACT can enhance the efficacy of surgery and radiotherapy, control the lesions of cervical cancer, and reduce the lymph node metastasis rate, parametrial infiltration rate and vascular invasion rate [6]. As previously reported, 
miRNAs are involved in drug resistance of cancer cells. For example, six miRNAs, including miR-21-5p, miR-20a5p, miR-103a-3p, miR-106b-5p, miR-143-5p, and miR215 , might be able to predict which patients benefit from adjuvant chemotherapy [7]. The miR-143 increased the sensitivity of human colorectal cancer cells to 5fluorouracil and the sensitivity of prostate cancer cells to docetaxel $[8,9]$. To determine whether miR-143 is sensitive to Taxol treatment in cervical cancer, the changes in the expression of miR-143 and its target protein bcl- 2 before and after NACT were detected in 24 patients who were treated effectively. Results showed that there was no significant difference in the expression of miR-143 in cervical cancer tissues after effective chemotherapy, suggesting that miR-143 was not involved in the effective response of cervical cancer tissue to Taxol. In the 24 effective chemotherapy cases, there was no significant decline of the bcl-2 positive expression after chemotherapy, suggesting that bcl-2, was not involved in the response of cervical cancer tissue to Taxol either. Taxol is able to stabilize the tubulin, inhibit the cell division and proliferation, and arrest the cancer cells at G2 and M phases, thus exerting its anticancer effect. The disturbance of the cell apoptosis pathway is beneficial to the tumor growth and invasion. Under the stimulation of cell growth factors, $\mathrm{Rb}$ is phosphorylated by the G1 phase protein cyclin D, and releases E2F, which promotes the gene transcription and progression of cell cycle. Studies indicated that miR-143 was one of the regulating genes of cyclin D1 [33]. In cervical cancer, miR-143 may promote apoptosis and inhibit tumor formation by targeting Bcl-2 [25]. Bcl-2 regulates the activation of p53 gene, and prevents the cell from arresting at the G1 phase [34]. Thus miR-143 could regulate cell cycles directly and indirectly to inhibit cancer cell growth, but may not act synergetically with Taxol. The exact relationship between miR-143 expression and cervical cancer sensitivity to Taxol still needs further investigation.

Cervical cancer is widely recognized to be caused primarily by persistent infection with high-risk HPV. However, HPV infection is not sufficient for cervical carcinogenesis and additional genetic events are involved in cervical carcinogenesis. It is reported that the human telomerase gene (hTERC) is involved in the progression of uterine cervical dysplasia to invasive cancer and can be used for the detection of high-grade cervical intraepithelial neoplasia (CIN) $[35,36]$. Han et al. reported that immunoreactivities of decreased D2-40 and increased p $16^{\mathrm{INK} 4 \mathrm{~A}}$ were correlated with higher grade of CIN [37]. Imura et al. found that Laminin-5 was a useful biomarker in the evaluation of invasiveness in cervical adenocarcinoma [38]. In this study, we analyzed the expression of miR-143, the correlation of miR-143 expression with clinical pathological features of cervical cancer, and the sensitivity of miR-143 to Taxol treatment. However, the role of miR-143 expression in evaluating the grade and invasiveness of cervical cancer is not studied and still needs further investigation.

In conclusion, the down regulation of miR-143 was a promoting factor for the occurrence of cervical SCC, and related to the infection of HPV16. The down regulation of miR-143 was also related with tumor size and lymph node metastasis. However, miR-143 was not involved in the effective responses of cervical SCC cells to Taxol.

\section{Competing interests}

The authors declare that they have no competing interests.

\section{Authors' contributions}

CYX carried out the quantitative real-time PCR, participated in HPV genotype detection, performed the statistical analysis and drafted the manuscript. ZW, CZF and ML carried out the immunohistochemistry assays. MCL conceived of the study, and participated in its design and coordination and helped to draft the manuscript. All authors read and approved the final manuscript.

\section{Acknowledgement}

This work was supported by the National Natural Science Foundation of China (Grant No. 81160278 and 81101555) and the Natural Science Foundation of Xinjiang (General Program, No. 2011211A070).

\section{Author details}

'Department of Gynecology, the First Affiliated Hospital of Xinjiang Medical University, No. 137 Liyushan South Road, Urumqi, Xinjiang 830054, P.R. China. ${ }^{2}$ Department of Pathology, the First Affiliated Hospital of Xinjiang Medical

University, Urumqi, Xinjiang 830054, P.R. China.

Received: 1 November 2013 Accepted: 2 April 2014

Published: 28 April 2014

\section{References}

1. Qian X, Yu J, Yin Y, He J, Wang L, Li Q, Zhang LQ, Li CY, Shi ZM, Xu Q, Li W, Lai LH, Liu LZ, Jiang BH: MicroRNA-143 inhibits tumor growth and angiogenesis and sensitizes chemosensitivity to oxaliplatin in colorectal cancers. Cell Cycle 2013, 12:1385-1394.

2. Wald Al, Hoskins EE, Wells Sl, Ferris RL, Khan SA: Alteration of microRNA profiles in squamous cell carcinoma of the head and neck cell lines by human papillomavirus. Head Neck 2011, 33:504-512

3. Lajer CB, Garnæs E, Friis-Hansen L, Norrild B, Therkildsen MH, Glud M, Rossing M, Lajer H, Svane D, Skotte L, Specht L, Buchwald C, Nielsen FC: The role of miRNAs in human papilloma virus (HPV)-associatedcancers: bridging between HPV-related head and neck cancer and cervical cancer. Br J Cancer 2012, 106:1526-1534.

4. Wang X, Tang S, Le SY, Lu R, Rader JS, Meyers C, Zheng ZM: Aberrant Expression of Oncogenic and TumorSuppressive MicroRNAs in Cervical Cancer Is Required for Cancer Cell Growth. PLoS One 2008, 7:e2557.

5. Deftereos G, Corrie SR, Feng Q, Morihara J, Stern J, Hawes SE, Kiviat NB: Expression of Mir-21 and Mir-143 in Cervical SpecimensRanging from Histologically Normal through to Invasive Cervical Cancer. PLoS One 2011, 6:e28423.

6. Yamakawa Y, Fujimura M, Hidaka T, Hori S, Saito S: Neoadjuvant Intraarterial Infusion Chemotherapy in Patients with Stage IB2-IIIB Cervical Cancer. Gynecol Oncol 2000, 77:264-270.

7. Zhang JX, Song W, Chen ZH, Wei JH, Liao YJ, Lei J, Hu M, Chen GZ, Liao B, Lu J, Zhao HW, Chen W, He YL, Wang HY, Xie D, Luo JH: Prognostic and predictive value of a microRNA signature in stage II colon cancer: a microRNA expression analysis. Lancet Oncol 2013, 14:1295-1306.

8. Borralho PM, Kren BT, Castro RE, da Silva IB, Steer CJ, Rodrigues CM: MicroRNA-143 reduces viability and increases sensitivity to 5-fluorouracil in HCT116 human colorectal cancer cells. FEBS J 2009, 276:6689-6700. 
9. Xu B, Niu X, Zhang X, Tao J, Wu D, Wang Z, Li P, Zhang W, Wu H, Feng N, Wang Z, Hua L, Wang X: miR-143 decreases prostate cancer cells proliferation and migration and enhances their sensitivity to docetaxel through suppression of KRAS. Mol Cell Biochem 2011, 350:207-213.

10. Szafranska AE, Davison TS, John J, Cannon T, Sipos B, Maghnouj A, Labourier E, Hahn SA: MicroRNA expression alterations are linked to tumorigenesis and non-neoplastic processes in pancreatic ductal adenocarcinoma. Oncogene 2007, 26:4442-4452.

11. Akagi I, Miyashita M, Ishibashi O, Mishima T, Kikuchi K, Makino H, Nomura T, Hagiwara N, Uchida E, Takizawa T: Relationship between altered expression levels of MIR21, MIR143, MIR145, and MIR205 and clinicopathologic features of esophageal squamous cell carcinoma. Dis Esophagus 2011, 24:523-530.

12. Zhang X, Liu S, Hu T, Liu S, He Y, Sun S: Up -regulated microRNA-143 transcribed by nuclear factor kappa $B$ enhances hepatocarcinoma metastasis by repressing fibronectin expression. Hepatology 2009, 50:490-499.

13. Fan X, Chen X, Deng W, Zhong G, Cai Q, Lin T: Up-regulated microRNA-143 in cancer stem cells differentiation promotes prostate cancer cells metastasis by modulating FNDC3B expression. BMC Cancer 2013, 13:1-11.

14. Ni Y, Meng L, Wang L, Dong W, Shen H, Wang G, Liu Q, Du J: MicroRNA143 functions as a tumor suppressor in human esophageal squamous cell carcinoma. Gene 2013, 517:197-204.

15. Lin T, Dong W, Huang J, Pan Q, Fan X, Zhang C, Huang L: MicroRNA-143 as a tumor suppressor for bladder cancer. J Urol 2009, 181:1372-1380.

16. Clapé $C$, Fritz $V$, Henriquet $C$, Apparailly F, Fernandez $P L$, Iborra F, Avancès $C$, Villalba M, Culine S, Fajas L: miR-143 interferes with ERK5 signaling, and abrogates prostate cancer progression in mice. PLOS One 2009, 4:e7542.

17. Chen X, Guo X, Zhang H, Xiang Y, Chen J, Yin Y, Cai X, Wang K, Wang G, Ba Y, Zhu L, Wang J, Yang R, Zhang Y, Ren Z, Zen K, Zhang J, Zhang CY: Role of miR-143 targeting KRAS in colorectal tumorigenesis. Oncogene 2009, 28:1385-1392.

18. Zhang $Y$, Wang Z, Chen M, Peng L, Wang X, Ma Q, Ma F, Jiang B: MicroRNA-143 Targets MACC1 to Inhibit Cell Invasion and Migration in Colorectal cancer. Mol Cancer 2012, 11:1-9.

19. Zhang H, Cai $X$, Wang $Y$, Tang H, Tong D, Ji F: microRNA-143 downregulated in osteosarcoma, promotes apoptosis and suppresses tumorigenicity by targeting Bcl-2. Oncol Rep 2010, 24:1363-1369.

20. Akao Y, Nakagawa Y, lio A, Naoe T: Role of microRNA-143 in Fas-mediated apoptosis in human T-cell leukemia Jurkat cells. Leuk Res 2009, 33:1530-1538.

21. Noguchi S, Yasui Y, Iwasaki J, Kumazaki M, Yamada N, Naito S, Akao Y: Replacement treatment with microRNA-143 and -145 induces synergistic inhibition of the growth of human bladder cancer cells by regulating $\mathrm{PI} 3 \mathrm{~K}$ / Akt and MAPK signaling pathways. Cancer Lett 2013, 28:353-361.

22. Wang XF, Shi ZM, Wang XR, Cao L, Wang YY, Zhang JX, Yin Y, Luo H, Kang CS, Liu N, Jiang T, You YP: MiR-181d acts as a tumor suppressor in glioma by targeting K-ras and Bcl-2. J Cancer Res Clin Oncol 2012, 138:573-584.

23. Xia L, Zhang D, Du R, Pan Y, Zhao L, Sun S, Hong L, Liu J, Fan D: miR-15b and miR-16 modulate multidrug resistance by targeting $B C L 2$ in human gastric cancer cells. Int J Cancer 2008, 123:372-379.

24. Lui WO, Pourmand N, Patterson BK, Fire A: Patterns of known and novel small RNAs in human cervical cancer. Cancer Res 2007, 67:6031-6043.

25. Liu L, Yu X, Guo X, Tian Z, Su M, Long Y, Huang C, Zhou F, Liu M, Wu X, Wang $X:$ miR-143 is downregulated in cervical cancer and promotes apoptosis and inhibits tumor formation by targeting $\mathrm{Bcl}-2$. Mol Med Rep 2012, 5:753-760

26. Liu R, Liao J, Yang M, Sheng J, Yang H, Wang Y, Pan E, Guo W, Pu Y, Kim SJ, Yin L: The Cluster of miR-143 and miR-145 Affects the Risk for Esophageal Squamous Cell Carcinoma through Co-Regulating Fascin Homolog 1. PLoS One 2012, 7:e33987.

27. Slaby O, Svoboda M, Fabian P, Smerdova T, Knoflickova D, Bednarikova M, Nenutil R, Vyzula R: Altered expression of miR-21, miR-31, miR-143 and miR-145 is related to clinicopathologic features of colorectal cancer. Oncology 2007, 72:397-402.

28. Ivanov S, Zervoudis S, Ivanov S: Metastatic cancer in transposed ovaries after radical Wertheim-Meigs hysterectomy for a stage I B and II A cervical cancer. Akush Ginekol (Sofiia) 2003, 42:22-24.

29. Munoz N, Bosch FX, Sanjose S: Epidemiologic classification of human papillomavirus type associated with cervical cancer. N Engl J Med 2003, 348:518-527.
30. Nambaru L, Meenakumari B, Swaminathan R, Rajkumar T: Prognostic significance of HPV physical status status and integration sites in cervical cancer. Asian Pac J Cancer Prev 2009, 10:355-360.

31. Boominathan L: The Tumor Suppressors P53, P63, and P73 are Regulators of MicroRNA Processing Complex. PLoS One 2010, 5:e10615.

32. Martinez I, Gardiner AS, Board KF, Monzon FA, Edwards RP, Khan SA: Human papillomavirus type16 reduces the expression of microRNA-218 in cervical carcinoma cells. Oncogene 2008, 27:2575-2582.

33. Lai VK, Ashraf M, Jiang S, Haider K: MicroRNA-143 is a critical regulator of cell cycle activity in stem cells with co-overexpression of Akt and angiopoietin-1 via transcriptional regulation of Erk5/cyclin D1 signaling Cell Cycle 2012, 11:767-777.

34. Ryan JJ, Prochownik E, Gottlieb CA, Apel IJ, Merino R, Nuñez G, Clarke MF: c-myc and bcl-2 modulate p53 function by altering p53 subcellular trafficking during the cell cycle. Proc Natl Acad Sci U S A 1994, 91:5878-5882.

35. Liu H, Liu S, Wang H, Xie X, Chen X, Zhang X, Zhang Y: Genomic amplification of the human telomerase gene (hTERC) associated with human papillomavirus is related to the progression of uterine cervical dysplasia to invasive cancer. Diagn Pathol 2012, 7:147.

36. Chen S, Yang Z, Zhang Y, Qiao Y, Cui B, Zhang Y, Kong B: Genomic amplification patterns of human telomerase RNA gene and C-MYC in liquid-based cytological specimens used for the detection of high-grade cervical intraepithelial neoplasia. Diagn Pathol 2012, 7:40.

37. Han H, Yang Y, Lu Z, He Q, Lin Z: Decreased D2-40 and increased p16INK4A immunoreactivities correlate with higher grade of cervical intraepithelial neoplasia. Diagn Pathol 2011, 6:59.

38. Imura J, Uchida Y, Nomoto K, Ichikawa K, Tomita S, lijima T, Fujimori T: Laminin-5 is a biomarker of invasiveness in cervical adenocarcinoma. Diagn Pathol 2012, 7:105.

doi:10.1186/1746-1596-9-88

Cite this article as: Chen et al:: Down regulation of miR-143 is related with tumor size, lymph node metastasis and HPV16 infection in cervical squamous cancer. Diagnostic Pathology 2014 9:88.

\section{Submit your next manuscript to BioMed Central and take full advantage of:}

- Convenient online submission

- Thorough peer review

- No space constraints or color figure charges

- Immediate publication on acceptance

- Inclusion in PubMed, CAS, Scopus and Google Scholar

- Research which is freely available for redistribution 